\title{
COVID-19: ВЛИЯНИЕ НА НАЦИОНАЛЬНУЮ ЭКОНОМИКУ
}

\section{COVID-19: IMPACT ON THE NATIONAL ECONOMY}

M. Griban

Summary. The article is devoted to the impact of coronavirus on the economy of the Russian Federation. The most affected sectors of the national economy, changes in currency and oil prices, and the main macroeconomic indicators are considered. The support measures taken by the Russian Government are studied.

Keywords: coronavirus, crisis, macroeconomic indicators, government support measures, affected industries.

\author{
Грибань Михаил Кириллович \\ Финансовый университет при Правительстве \\ Российской Федерации, г. Москва, РФ \\ griban17@yandex.ru
}

Аннотация. Статья посвящена влиянию коронавируса на экономику Российской Федерации. Рассмотрены наиболее пострадавшие отрасли национальной экономики, изменения котировок валют и нефти, основные макроэкономические показатели. Изучены меры поддержки, принятые Правительством РФ.

Ключевые слова: коронавирус, кризис, макроэкономические показатели, государственные меры поддержки, пострадавшие отрасли.

года (Рис. 1). Это не соответствует бюджетным прогнозам аналитиков на 2020 и 2021 годы. Согласно федеральному закону № 459-Ф3 «О федеральном бюджете на 2019 год и на плановый период 2020 и 2021 годов» в России предполагаемый экономический рост должен был составить более 2\% [1]. При этом в расчетах использовался курс доллара в 63,9 рубля и средняя цена нефти в 57,7 долларов за баррель. Глава счетной палаты А.Л. Кудрин заметил, что основной бюджетный прогноз министерства экономического развития полностью утратил свою актуальность в связи с новыми котировками. Также существует риск девальвации рубля, возникший из-за того, что бюджет может не сойтись по нефтегазовым причинам.

Дальнейшее развитие COVID-19 вызвало закрытие границ, что разрушает международные связи, разрывает цепочки поставок и производства. Особенно страдает отрасль высоких технологий, создание которых предполагает совместную работу производителей из разных стран. Упал спрос на природные ресурсы России. Согласно прогнозам аналитиков Bloomberg Economics, Pocсия может потерять 4,35 триллиона рублей. В половине сценариев развития глобальной пандемии в России произойдет рецессия.

Правительство РФ объявило о мерах поддержки российской экономики из-за коронавируса 16.03.2020 г. Среди основных мер были создание антикризисного фонда в размере 300 млрд. руб., введение налоговых льгот для туристической и авиаотрасли, а также доступ к льготным кредитам. Стоит также выделить льготный кредит предприятиям под 0\% на выплаты зарплат сотрудникам, при условии, что будет сохранено хотя бы $90 \%$ от штата. Та- 

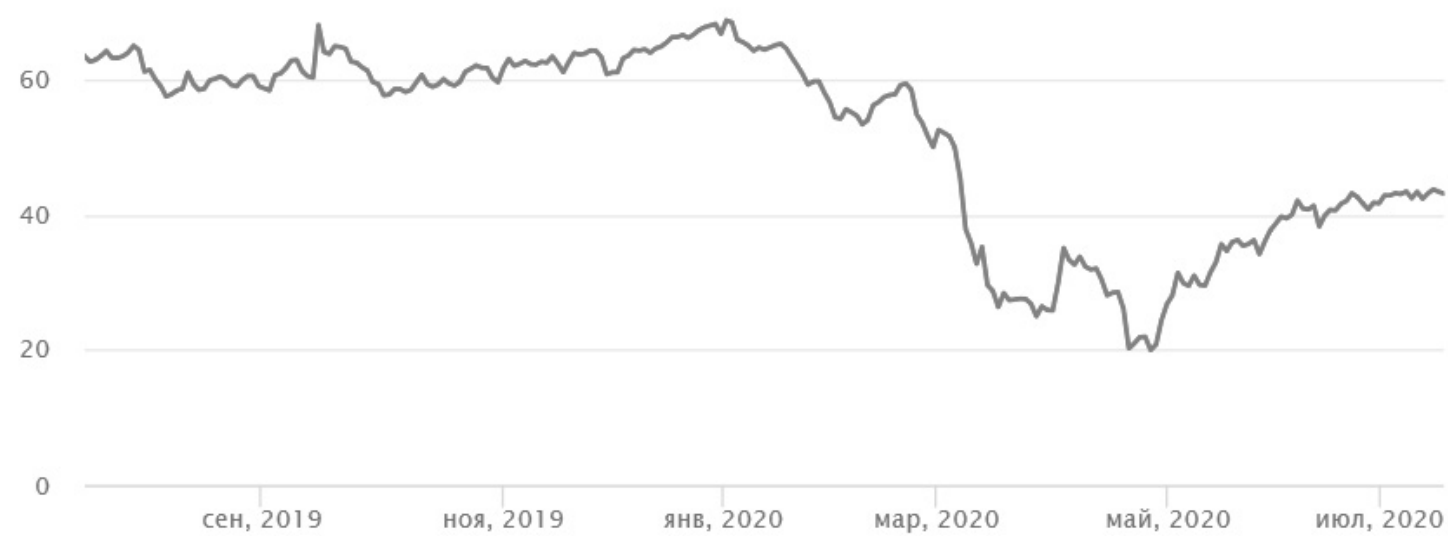

Рис. 1. Цены на нефть (в долларах)

Источник: https://yandex.ru/news/quotes/1006.html

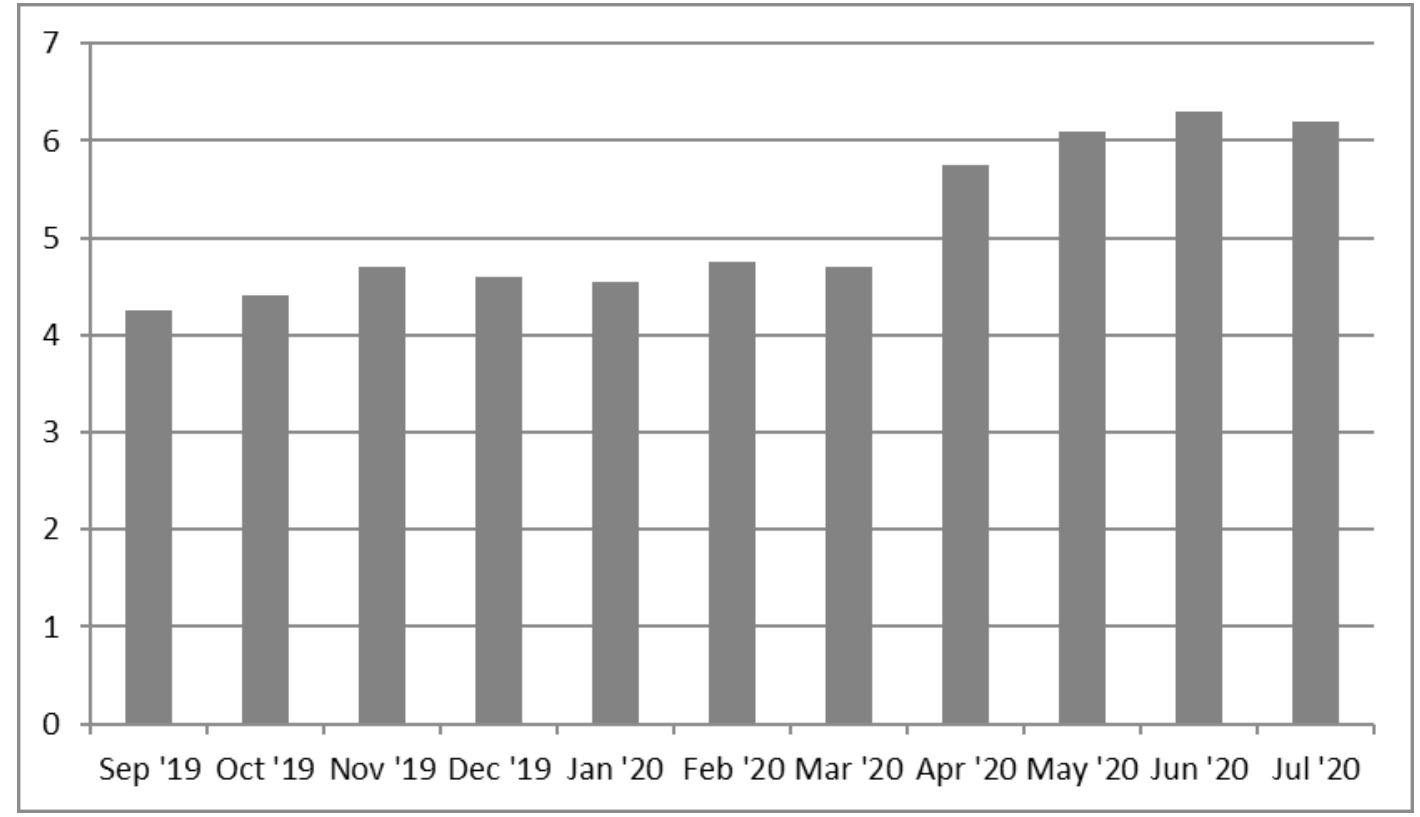

Рис. 2. Уровень безработицы в России (в \%)

Источник: https://ru.investing.com/

кая мера была направлена на сохранение рабочих мест и борьбу с безработицей. Однако, уровень безработицы оказался значительно выше аналогичного показателя по месяцам прошлого года, при том, что государство приняло меры для борьбы с безработицей, а в июне началось ослабление карантинных мер и открытие предприятий. Так, по данным центра занятости, в мае этого года на одну вакансию претендовало 2,3 человека, что в 6,6 раз больше, чем в мае прошлого года; 156,6 тысяч человек имели статус безработного. При этом за май безработными было признано 81,5 тысяч человек, что в 20,2 раза больше, чем в мае 2019 года. В июне показатель безработицы составил 6,3\% (Рис. 2). Михаил Мишустин подписал постановление № 485 от 12.04.2020, которое предполагает максимальные выплаты по безработице (12130 рублей) гражданам, потерявшим работу после 01.03.2020 [5]. Также поддержку получили семьи с детьми до 16 лет: им положены выплаты на каждого ребенка,- мера была утверждена постановлением № 919 от 25.06.2020 [6]. 
В целях защиты экономики государство Постановлением Правительства РФ от 03.04.2020 г. № 434 «Об утверждении перечня отраслей российской экономики, в наибольшей степени пострадавших в условиях ухудшения ситуации в результате распространения новой коронавирусной инфекции» выделило девять отраслей, наиболее нуждающихся в государственной поддержке [2]. Среди них:

- Авиаперевозки, аэропорты, автоперевозки. С закрытием границ отрасль простаивала и несла огромные убытки. Государство выделило три миллиарда рублей на субсидирование региональных авиаперевозок. Сейчас, когда воздушные границы постепенно открываются и начался летний туристический сезон, на фоне ослабления карантинных мер, отрасль восстанавливается, увеличилось количество региональных авиаперевозок.

- Культура, организация досуга и развлечений. Отрасль серьезно пострадала из-за резкого снижения потребителей: как туристов, так и локальных потребителей. Летом театры, кинотеатры, музеи открылись для посетителей с ограничениями, такими как лимит количества одновременных посетителей и соблюдение социальной дистанции. Это серьезно ударило по потенциальному потоку посетителей, следовательно, максимальный возможный доход тоже снизился. На практике спрос на отрасль оказался очень низким, поскольку сбережения и реальный доход населения за период самоизоляции снизились.

- Физкультурно-оздоровительная деятельность и спорт. После простоя в период самоизоляции отрасль постепенно восстанавливается. Переменные издержки отрасли находятся на низком уровне, поэтому потери оказались невелики. Более того, после длительного нахождения дома люди проявили спрос на физкультурно-оздоровительную деятельность.

- Деятельность туристических агентств и прочих организаций, предоставляющих услуги в сфере туризма. После июньского ослабления ограничений, летний сезон позволил туристическим агентствам начать работу после карантинного застоя. Михаил Мишустин 22.07.2020 г. во время выступления в Госдуме сообщил, что государство возместит часть расходов на отдых гражданам, которые до конца 2020 года проведут отпуска в регионах России.

- Гостиничный бизнес. Отрасль серьезно пострадала из-за отсутствия иностранных туристов. Относительно благополучная ситуация с гостиничным бизнесом находится в наиболее популярных местах отдыха россиян - Крыму и Сочи.
- Общественное питание. Многие предприятия отрасли закрылись, посчитав, что работа с ограничениями принесет больший убыток, чем дальнейший простой.

- Организации дополнительного образования, негосударственные образовательные учреждения. В период самоизоляции отрасль получила возможность опробовать дистанционное обучение на основе современных информационных технологий. После ослабления ограничений многие организации стали работать и в очном режиме.

- Организация конференций и выставок. Отрасль, предполагающая собрание большого количества людей в одном месте, плохо себя чувствует даже после летнего ослабления ограничений. Некоторые конференции стали проводится в режиме онлайн.

- Предоставление бытовых услуг населению (ремонт, стирка, химчистка, услуги парикмахерских и салонов красоты). После весеннего простоя, летом после снятия ограничений на отрасль образовался высокий спрос. Например, услуги парикмахерских и салонов красоты востребованы людьми, не имевшим доступ к подобным услугам в течение периода самоизоляции.

Перечень пострадавших отраслей пополнялся несколько раз. Так, в него были внесены СМИ, железнодорожные и морские пассажирские перевозки [7]. Спрос на последние сильно уменьшился из-за карантинных ограничений. В первой половине апреля на поездах дальнего следования пассажиропоток снизился на 77\% к аналогичному периоду прошлого года. Похожая ситуация наблюдалась в сегменте пассажирских перевозок морским и внутренним водным транспортом, поэтому было решено внести эти сектора в перечень.

Стоит отметить, что больше всего отрицательному воздействию пандемии COVID-19 оказался подвержен малый бизнес. Государство сосредоточило усилия на возможности удержать малый бизнес на плаву и выпустило комплекс соответствующих мер. Из наиболее значимых мер стоит отметить введение моратория на банкротство предприятий и мораторий на выплаты по страховым взносам на три месяца, а также льготные кредиты предприятиям под 0\% на выплату зарплат сотрудникам, причем если предприятие сохранит хотя бы 90\% сотрудников, кредит будет списан [3]. Также все предприятия получили следующие льготы: снижение тарифов страховых взносов с $30 \%$ до 15\%, перенос сроков сдачи отчетности по налогам и бухгалтерской отчетности, сокращение плановых и внеплановых проверок госорганов, продление сроков действия разрешений на строительство, лицензий на продажу алкоголя и некоторые другие разрешительные документы. Малые и средние предпри- 


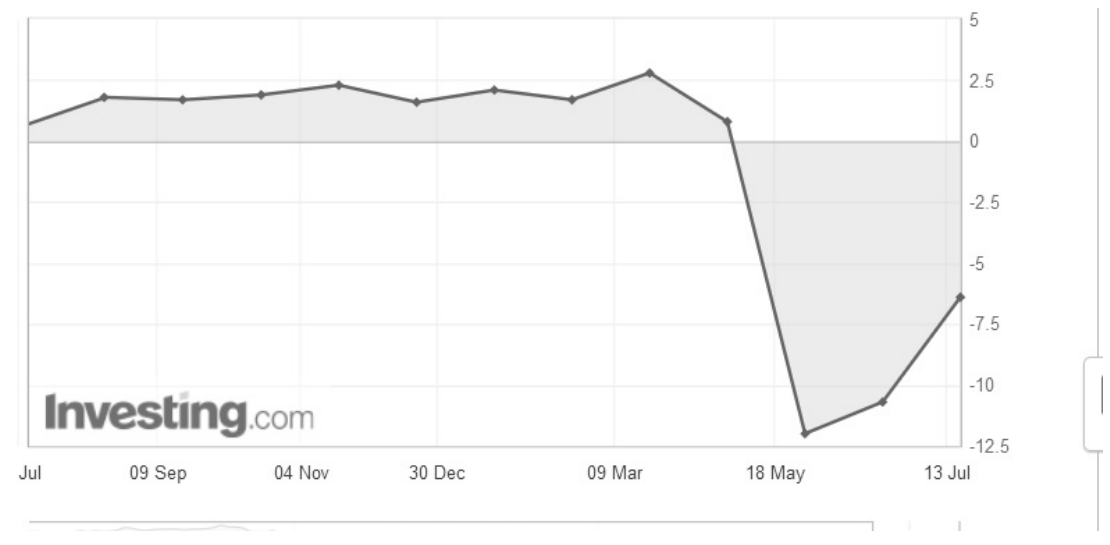

Рис. 3. ВВП России (в \%)

Источник: https://ru.investing.com/

ятия из списка пострадавших областей, утвержденным постановлением № 434, получили ряд дополнительных льгот: отсрочки и рассрочки по налогам и взносам, возможность получить субсидии за апрель и май, льготное кредитование, кредитные каникулы для заемщиков и отсрочки по кредитам по госпрограмме, арендные каникулы для арендаторов коммерческой недвижимости и арендаторов госимущества [4]. Апрель был объявлен нерабочим месяцем с сохранением заработной платы.

Эксперты оценили потери от нерабочего месяца в 2-2,5\% от ВВП. Затем в мае ВВП России упал до -12\%это больше, чем во времена мирового кризиса 2008 года. В июне начался постепенный рост, который несколько ускорился в июле (Рис. 3).

По мере распространения инфекции по России, все большее значение приобретал вопрос регулятивного характера в регионах: отменять или продлевать ограничительные меры, ужесточать или смягчать действия. В.В.Путин поручил главам регионов самим решать, как действовать, поскольку ситуация в регионах развивается по-разному. Поэтому разные регионы показали разную эффективность борьбы с инфекцией, соответственно экономики регионов тоже отреагировали по-разному. Постановлением № 619 от 30.04.2020 г. регионы в 2020 году были освобождены от платежей по бюджетным кредитам [8]. Освободившиеся средства регионы смогут использовать для ликвидации последствий распространения COVID-19, а также в качестве компенсации потерь части налоговых и неналоговых доходов. Мера поможет обеспечить стабильность региональных бюджетов в условиях сложной социально-экономической ситуации.

Для физических лиц за период пандемии особо актуальным стал вопрос грамотного вложения денег. Как известно, большая часть населения предпочитает бан- ковские вклады. Но сегодня банковские вклады становятся все менее и менее привлекательными. После многочисленных снижений ключевой ставки в 2019 году, 24 июля 2020 года Центральный Банк вновь снизил ключевую ставку до уровня в 4,25\% - самый низкий уровень за всю историю РФ. По итогам первой декады июля, средняя максимальная ставка по вкладам десяти крупнейших банков России упала до рекордно низкой отметки в 4,63\%. При этом еще в декабре 2019-го этот показатель находился на уровне 6,01\%. Более того, весной Правительство сообщило о предстоящем налоге на вклады, который начнет действовать с 2021 года. Все это привело к снижению привлекательности банковских вкладов. В июне вклады физических лиц в банках сократились еще на 104 млрд. рублей, а с начала года — на 594 млрд. рублей, сообщает ЦБ.

Если ключевая ставка продолжит снижение и к концу года составит менее 4\%, вопрос целесообразности хранения средств на банковском вкладе как на самом надежном и эффективном, защищающим от инфляции инструменте ставится под сомнение. Весьма вероятно падение депозитных ставок вплоть до 2-3\% годовых, когда уровень инфляции может оказаться ниже таргета ЦБ и составить примерно $3 \%$.

Между тем, из-за кризиса на фондовом рынке, вызванного пандемией, инвесторы предпочли перевести средства в наиболее безопасные активы - одним из них стало золото. 9 июля его котировки поднялись до уровня 1820 долларов за тройскую унцию - самого высокого уровня с 2011 года. Это побуждает все больше людей покупать этот драгоценный металл. Более того, инвестиционная схема с возможностью открыть индивидуальный брокерский счет (ИИС) с получением ежегодного налогового вычета вплоть до 52 тыс. руб. и вложениями в облигации федерального займа (ОФЗ) для получения ежегодного купонного дохода привлекает все больше мелких 
пассивных инвесторов. По результатам исследования НАФИ [9] примерно 30\% граждан закроют свои вклады, если ставки по ним продолжат снижаться. При этом среди вкладчиков в возрасте 21-35 лет закрыть вклады готовы 36\% респондентов, а среди тех, кому за 55 лет, только $25 \%$. Многие опрошенные хотят инвестировать свои средства в другие инструменты с целью получения более высокой доходности. Так, 7\% респондентов планируют вложить свои средства в золото, 6\% - в облигации, а $4 \%$ - в недвижимость.

Пандемия COVID-19 стала серьезным вызовом российской экономике. Были затронуты практически все сферы социально-экономической жизни государства: производство, взаимоотношения работников и работодателей, финансовые рынки, состояние национальной валюты, торговый баланс страны.

Проанализировав меры, предпринятые Правительством РФ и макроэкономические показатели, можно сде- лать следующие выводы. Страна начинает осознавать, в каком направлении ей надо развиваться, какие наиважнейшие сферы деятельности необходимо совершенствовать, чтобы быть готовой к вызовам современности. Правительству необходимо внимательно пересмотреть требования, предъявляемые к различным сегментам бизнеса, чтобы не допустить их развала. Необходимо также принятие соответствующих мер по ликвидации негативных последствий кризиса. Эффективная реакция на социально-экономические последствия кризиса COVID-19 требует не только активного и целенаправленного макроэкономического воздействия, но и комплекса корректирующих мер политики и институциональных реформ, необходимых для того, чтобы заложить основы для будущего экономического роста. Возможно, некоторые нововведения, такие как системы дистанционной работы и обучения, продолжат свое развитие и в будущем станут привычными и востребованными. В целом, российская экономика начинает постепенно восстанавливаться после падения.

\section{ЛИТЕРАТУРА}

1. Федеральный закон «0 федеральном бюджете на 2019 год и на плановый период 2020 и 2021 годов» от 29.11.2018 № 459-Ф3 (последняя редакция) // СПС «Консультант-Плюс».

2. «0б утверждении перечня отраслей российской экономики, в наибольшей степени пострадавших в условиях ухудшения ситуации в результате распространения новой коронавирусной инфекции»: Постановление Правительства РФ от 03.04.2020 № 434 (ред. от 18.04.2020) // СПС «Консультант-Плюс».

3. «0б утверждении Правил предоставления в 2020 году субсидий из федерального бюджета российским кредитным организациям на обеспечение отсрочки от платежа по кредитам, выданным субъектам малого и среднего предпринимательства»: Постановление Правительства РФ от 02.04 .2020 № 410 (ред. от 24.04.2020) // СПС «Консультант-Плюс».

4. «0б утверждении Правил предоставления субсидий из федерального бюджета российским кредитным организациям на возмещение недополученных ими доходов по кредитам, выданным в 2020 году юридическим лицам и индивидуальным предпринимателям на неотложные нужды для поддержки и сохранения занятости»: Постановление Правительства РФ от 02.04.2020 № 422 (ред. от 24.04.2020) // СПС «Консультант-Плюс».

5. «0 внесении изменения в постановление Правительства Российской Федерации от 27 марта 2020 г. № 346 и приостановлении действия отдельных положений Временных правил регистрации граждан в целях поиска подходящей работы и в качестве безработных, а также осуществления социальных выплат гражданам, признанным в установленном порядке безработными»: Постановление Правительства РФ от 12.04 .2020 № 485 // СПС «Консультант-Плюс».

6. «0 внесении изменений в постановление Правительства Российской Федерации от 9 апреля 2020 г. № 474»: Постановление Правительства РФ от 25.06 .2020 № 919 // СПС «Консультант-Плюс».

7. «0 внесении изменений в раздел 1 перечня отраслей российской экономики, в наибольшей степени пострадавших в условиях ухудшения ситуации в результате распространения новой коронавирусной инфекции»: Постановление Правительства РФ от 26.06 .2020 № 927 // СПС «Консультант-Плюс». а. «0 внесении изменений в некоторые акты Правительства Российской Федерации»: Постановление Правительства РФ от 30.04 .2020 № 619 в действующей редакции // СПС «Консультант-Плюс». 6. Аналитический центр НАФИ [сайт]: URL: https://nafi.ru/ (дата обращения: 17.07.2020).

8. Правительство России [сайт]: URL: http://government.ru/ (дата обращения: 17.07.2020).

( Грибань Михаил Кириллович ( griban17@yandex.ru ).

Журнал «Современная наука: актуальные проблемы теории и практики» 